02

\title{
Люминесцентные свойства монокристаллов сапфира, облученных импульсным ионным пучком $\mathrm{Fe}^{10+}$
}

\author{
(C) Г.Р. Рамазанова ${ }^{1}$, Д.В. Ананченко ${ }^{1, \uparrow}$, С.В. Никифоров ${ }^{1}$, М.Ф. Герасимов ${ }^{1}$, А.В. Ищенко ${ }^{1}$, \\ А.К. Даулетбекова ${ }^{2}$, Ж.Т. Карипбаев ${ }^{2,3}$, Г.А. Ахметова-Абдик ${ }^{12}$, М.В. Здоровец ${ }^{1,2,4}$ \\ ${ }^{1}$ Уральский фредеральный университет им. Первого Президента России Б.Н. Ельцина, \\ 620002 Екатеринбург, Россия \\ ${ }^{2}$ Евразийский национальный университет им. Л.Н. Гумилева, \\ 010008 Нур-Султан, Казахстан \\ ${ }^{3}$ Национальный исследовательский Томский политехнический университет, \\ 634050 Томск, Россия \\ ${ }^{4}$ Институт ядерной фризики, \\ 050032 Алматы, Казахстан \\ I e-mail: d.v.ananchenko@urfu.ru \\ Поступила в редакцию 08.02.2021 г. \\ В окончательной редакции 13.04.2021 г. \\ Принята к публикации 29.04.2021 г.
}

Исследованы оптические и люминесцентные свойства монокристаллов сапфира, облученных импульсным пучком ионов $\mathrm{Fe}^{10+}$ с энергией $200 \mathrm{keV}$. Результаты измерения оптического поглощения, фотолюминесценции и импульсной катодолюминесценции указывают на процессы образования $F$ - и $F^{+}$-центров в кристаллах, подверженных ионному облучению. Люминесценция центров $F$-типа немонотонно зависит от дозы облучения, что объяснятся эффектом концентрационного тушения. Термолюминесценция облученных ионами $\mathrm{Fe}^{10+}$ кристаллов наблюдается в диапазоне температур 350-750 K. Разложение кривых термолюминесценции на элементарные пики общего порядка кинетики позволило получить значения кинетических параметров ловушек. Обсуждаются перспективы использования кристаллов сапфира в термолюминесцентной дозиметрии импульсных ионных пучков.

Ключевые слова: монокристаллы сапфира, ионный пучок, радиационно-индуцированные дефекты, ионы железа, люминесценция.

DOI: $10.21883 /$ OS.2021.08.51196.1887-21

\section{Введение}

Монокристаллический сапфир $\left(\alpha-\mathrm{Al}_{2} \mathrm{O}_{3}\right)$ нашел широкое применение в электронной технике благодаря уникальному сочетанию своих физико-химических свойств. Этот широкозонный диэлектрик обладает высокой радиационной, термической (температура плавления $2050^{\circ} \mathrm{C}$ ) и химической стойкостью [1], что позволяет использовать его в условиях высоких температур и сильных радиационных полей. Монокристаллы сапфира используются в качестве диэлектрических подложек интегральных микросхем, работающих на АЭС и в космосе [2], а также оптических окон, применяемых в термоядерных реакторах [3].

Известно, что облучение сапфира корпускулярными видами излучений (протоны, нейтроны, ионы) с высокими энергиями [4-8] приводит к образованию в анионной и катионной подрешетке вакансий по ударному механизму. Согласно работам [9-11], диапазоны экспериментальных и рассчитанных значений пороговой энергии смещения в $\mathrm{Al}_{2} \mathrm{O}_{3}$ по ударному механизму составляют для алюминия около $20-30 \mathrm{eV}$, а для кислорода 50-90 eV. В случае, если энергия налетающих частиц превышает пороговую энергию смещения, в материа- ле образуются дефекты по Френкелю, представляющие собой пару, состоящую из вакансии и междоузельного иона, смещенного из узла кристаллической решетки. Дефекты в анионной подрешетке (кислородные вакансии в различных зарядовых состояниях), образуемые при таком радиационном окрашивании, определяют оптические и люминесцентные свойства сапфира. Кислородные вакансии в $\alpha-\mathrm{Al}_{2} \mathrm{O}_{3}$ способны захватывать электроны. Вакансии, захватившие два и один электрон, образуют соответственно $F$ - и $F^{+}$-центры $[12,13]$. В кристаллах с высокой концентрацией $F$ - и $F^{+}$-центров также существует вероятность образования и более сложных дефектных структур, а именно агрегатных центров $F_{2}$ типа [14].

В настоящее время известно достаточное количество публикаций, посвященных изучению люминесцентных и оптических свойств монокристаллов сапфира, подвергнутых непрерывному облучению высокоэнергетичными ионами. В статье [8] авторы проводили исследование оптического поглощения (ОП) и термолюминесценции (ТЛ) монокристаллов $\mathrm{Al}_{2} \mathrm{O}_{3}$, облученных ионами ${ }^{238} \mathrm{U}$ с энергией $2.4 \mathrm{GeV}$ (флюенс $10^{12} \mathrm{ion} / \mathrm{cm}^{2}$ ). Установлено, что данный вид облучения приводит к генерации в $\mathrm{Al}_{2} \mathrm{O}_{3}$ $F$-центров (максимум поглощения при $6.05 \mathrm{eV}$ ) и $F^{+}$- 
центров $(4.8$ и $5.4 \mathrm{eV})$. В работе [15] методами ОП и фотолюминесценции (ФЛ) было также обнаружено образование центров $F$-типа в $\alpha-\mathrm{Al}_{2} \mathrm{O}_{3}$, облученном ионами серебра с энергиями 100 и $190 \mathrm{MeV}$ (флюенс от $1 \cdot 10^{11}$ до $1 \cdot 10^{13}$ ion $\left./ \mathrm{cm}^{2}\right)$. Имплантация прозрачных монокристаллов сапфира ионами церия (с энергией $100 \mathrm{keV})$ была исследована в статье [16]. Авторы работы в спектрах ионолюминесценции, вызванной бомбардировкой ионами $\mathrm{Ar}$ с плотностью тока $0.05 \mu \mathrm{A} / \mathrm{cm}^{2}$, наблюдали три полосы на 340,390 и $420 \mathrm{~nm}$, указывающие на образование $F^{+}$-, $F_{2}$ - и $F$-центров соответственно. Генерация в $\mathrm{Al}_{2} \mathrm{O}_{3}$ радиационно-индуцированных дефектов $F$-типа также возможна при облучении легкими ионами. Так, например в статье [17] была зарегистрирована ионолюминесценция $F$-, $F^{+}$- и $F_{2}$-центров во время облучения монокристаллов сапфира ионными пучками $\mathrm{H}^{+}, \mathrm{H}^{2+}, \mathrm{He}^{+}, \mathrm{O}^{+}$и $\mathrm{Ar}^{+}$с энергией около $3 \mathrm{MeV}$.

Стоит заметить, что значительно меньше исследованы закономерности образования дефектов в монокристаллах сапфира при импульсном ионном облучении. Особенностью импульсного ионного облучения является то, что при его воздействии на образец попадает большое количество энергии, это приводит к быстрому нагреву сапфира вплоть до поверхностного плавления [18]. В статье [19] была исследована ионолюминесценция пластин $\mathrm{Al}_{2} \mathrm{O}_{3}$ (чистотой 99.9\%), возбуждаемая импульсным ионным пучком (ИИП) дейтерия наносекундной длительности с энергией $250 \mathrm{keV}$. Установлено, что этой энергии ионов дейтерия достаточно для генерации $F$ и $F^{+}$-центров в сапфире. Методами ОП, ФЛ и импульсной катодолюминесценции (ИКЛ) исследовались монокристаллы $\alpha-\mathrm{Al}_{2} \mathrm{O}_{3}$, облученные ИИП $\mathrm{C}^{+} / \mathrm{H}^{+}$с энергией $300 \mathrm{keV}$ и длительностью импульса $80 \mathrm{~ns}$ [20]. В работе было обнаружено, что такой тип воздействия приводит к интенсивной генерации радиационно-индуцированных дефектов $F$ - и $F_{2}$-типа. В работе [21] была исследована термическая стабильность дефектов $F$-типа, образуемых в $\alpha-\mathrm{Al}_{2} \mathrm{O}_{3}$, облученном ИИП $\mathrm{C}^{+} / \mathrm{H}^{+}$.

На настоящий момент известны работы, посвященные исследованию непрерывного облучения монокристаллического сапфира ионами железа, но нет достаточной осведомлённости о последствиях импульсного радиационного воздействия на сапфир этим типом ионов. Так, например, в статьях $[22,23]$ исследовались монокристаллы $\alpha-\mathrm{Al}_{2} \mathrm{O}_{3}$, обученные ионами железа с энергиями $3.8 \mathrm{MeV}$ и $1.157 \mathrm{GeV}$ соответственно. Авторами работ методами ОП, ФЛ и ЭПР в облученных кристаллах были выявлены центры $F$ - и $F_{2}$-типа.

Отдельный интерес представляет исследование воздействия ИИП $\mathrm{Fe}^{10+}$ на $\alpha-\mathrm{Al}_{2} \mathrm{O}_{3}$. Полосы железа $\mathrm{Fe}^{10+}$ были обнаружены в рентгеновских спектрах звездных объектов, также метастабильные переходы $\mathrm{Fe}^{10+}$ в спектральном диапазоне $100-300 \mathrm{~nm}$ наблюдались в солнечном спектре [24]. Возможности использования монокристаллов сапфира в космосе в качестве диэлектрических подложек интегральных микросхем стимулируют интерес изучения закономерностей формирования дефектов во время импульсного облучения монокристаллов $\alpha$ $\mathrm{Al}_{2} \mathrm{O}_{3}$ ионами $\mathrm{Fe}^{10+}$.

Целью представленной работы являлось изучение влияния импульсного ионного облучения $\mathrm{Fe}^{10+}$ на образование дефектов в сапфире методами люминесцентной и оптической спектроскопии.

\section{Образцы и методы исследований}

Исследовались образцы стехиометрических высокочистых (99.99\%) монокристаллов $\alpha-\mathrm{Al}_{2} \mathrm{O}_{3}$, выращенных методом Киропулоса. Образцы были предостав-

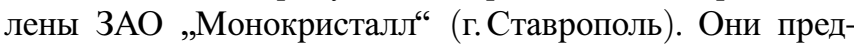
ставляли собой оптически прозрачные двухстороннеполированные квадратные пластины толщиной $0.75 \mathrm{~mm}$ и размером $5 \mathrm{~mm}$. Концентрации наиболее оптически активных примесей $\mathrm{Ti}$ и $\mathrm{Cr}$ в исследуемых образцах, согласно данным производителя, не превышали $0.5 \mathrm{ppm}$.

Радиационно-индуцированные дефекты $F$-типа в сапфире создавались посредством его облучения ИИП $\mathrm{Fe}^{10+}(200 \mathrm{keV})$ на ускорителе тяжелых ионов DC-60 (Нур-Султан, Республика Казахстан). Длительность импульса ИИП составляла $\tau=18 \mathrm{~ns}$, а период $\Delta t=60 \mathrm{~ns}$. Циклотрон позволяет ускорять ионы в диапазоне масс от ${ }^{6} \mathrm{Li}$ до ${ }^{132} \mathrm{Xe}$. Значения флюенса варьировали в интервале от $10^{12}$ до $10^{14} \mathrm{ion} / \mathrm{cm}^{2}$. Для пересчета флюенса в дозу облучения использовали формулу [25]

$$
D=\frac{1.6 \cdot 10^{-19} E \Phi}{\rho R},
$$

где $E-$ полная энергия ионов $(\mathrm{eV}), \Phi-$ значение флюенса $\left(\mathrm{ion} / \mathrm{m}^{2}\right), \rho$ - плотность сапфира $\left(3980 \mathrm{~kg} / \mathrm{m}^{3}\right)$, $R$ - длина пробега ионов в сапфире $(\mathrm{m})$.

Для расчета среднего пробега ионов $\mathrm{Fe}^{10+}$ c энергией $200 \mathrm{keV}$ в мишени из $\alpha-\mathrm{Al}_{2} \mathrm{O}_{3}$ было произведено моделирование в программе SRIM [26]. Рассчитанная длина среднего пробега ионов $R$ составила $952 \AA$. Для трех используемых в работе значений флюенса ИИП $\left(10^{12}, 10^{13}\right.$ и $\left.10^{14} \mathrm{ion} / \mathrm{cm}^{2}\right)$ по формуле (1) были рассчитаны три дозы облучения $\left(D_{1}=8.4 \cdot 10^{5} \mathrm{~Gy}\right.$, $D_{2}=8.4 \cdot 10^{6}$ Gy и $\left.D_{3}=8.4 \cdot 10^{7} \mathrm{~Gy}\right)$.

Спектры ОП регистрировались с использованием двухлучевого спектрофотометра Lambda35 [27]. Измерения происходили со скоростью сканирования $120 \mathrm{~nm} / \mathrm{min}$ в спектральном диапазоне от 190 до $350 \mathrm{~nm}$ при комнатной температуре. Для работы в этом спектральном диапазоне в спектрофотометре в качестве источника излучения применялась дейтериевая лампа.

Регистрация спектров ИКЛ кристаллов осуществлялась с использованием катодолюминесцентного импульсного анализатора веществ „КЛАВИ“. Возбуждение люминесценции в образцах осуществлялось при их облучении на воздухе при комнатной температуре электронным пучком длительностью $2 \mathrm{~ns}$, с максимальной энергией электронов $130 \pm 10 \mathrm{keV}$ и плотностью 


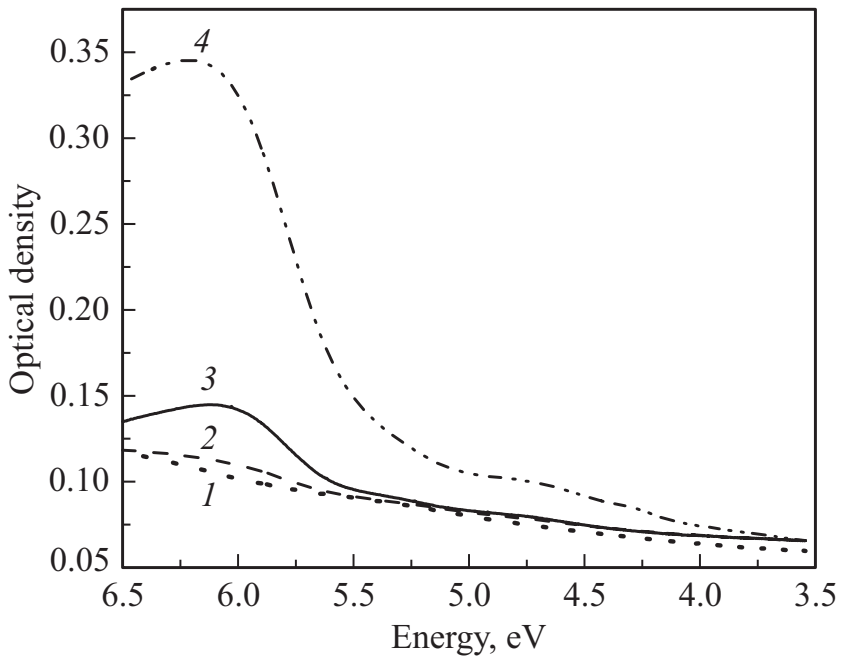

Рис. 1. Спектры ОП исходных кристаллов сапфира (1) и образцов, облученных разными дозами ИИП $\mathrm{Fe}^{10+}: \quad D_{1}=8.4 \cdot 10^{5} \mathrm{~Gy} \quad(2), \quad D_{2}=8.4 \cdot 10^{6} \mathrm{~Gy} \quad(3)$, $D_{3}=8.4 \cdot 10^{7} \mathrm{~Gy}(4)$.

тока $60 \mathrm{~A} / \mathrm{cm}^{2}$. Спектральный диапазон регистрации составлял от 350 до $750 \mathrm{~nm}$, спектральное разрешение $2 \mathrm{~nm}$. Погрешность измерения длин волн в положении наибольшего усиления электронно-оптического преобразователя равна $\Delta \lambda= \pm 0.75 \mathrm{~nm}$ [28].

Спектры возбуждения и свечения ФЛ в работе регистрировались спектрометром LS-55 при комнатной температуре. Возбуждение ФЛ осуществлялось ксеноновой разрядной лампой мощностью $150 \mathrm{~W}$, работающей в импульсном режиме с частотой $50 \mathrm{~Hz}$. ФЛ регистрировалась с помощью фотоумножителя R928, спектральный диапазон чувствительности которого находится в пределах 200-900 nm с максимумом при $400 \mathrm{~nm}$ [29]. Поскольку время жизни $F^{+}$-центров мало $(\approx 1.7 \mathrm{~ns})$ [19], то измерение ФЛ $F^{+}$-центров осуществлялось в режиме флюоресценции, скорость сканирования составляла $100 \mathrm{~nm} / \mathrm{min}$.

ТЛ измерялась в режиме линейного нагрева со скоростью $2 \mathrm{~K} / \mathrm{s}$ в интервале температур 60-600 $\mathrm{C}$. Для регистрации свечения ТЛ использовались фотоэлектронные умножители ФЭУ-130 (спектральная область чувствительности 200-650 nm с максимумом при 400-420 nm) и ФЭУ-142 (спектральная область чувствительности $112-365 \mathrm{~nm})$. За счет поглощения воздуха для ФЭУ-142 спектральная область чувствительности сокращается до 200-365 $\mathrm{nm}$.

\section{Результаты и обсуждение}

\section{1. Оптическое поглощение}

На рис. 1 представлены результаты изменения спектров ОП образцов сапфира до и после облучения ИИП $\mathrm{Fe}^{10+}$ с разной величиной дозы. Резкое увеличение оптической плотности в интервале энергий 4.5-6.5 eV $(190-275 \mathrm{~nm})$ с увеличением дозы облучения может свидетельствовать об образовании в монокристаллах сапфира радиационно-индуцированных дефектов. Максимальное ОП наблюдается у образцов, облученных ИИП $\mathrm{Fe}^{10+}$ с дозой $8.4 \cdot 10^{7} \mathrm{~Gy}$.

Чтобы идентифицировать типы образующихся при облучении ИИП дефектов в исследуемых образцах, была рассчитана радиационно-индуцированная оптическая плотность (РИОП). Для ее получения из спектров ОП облученных образцов вычитали спектр ОП исходного образца. Спектры РИОП были разложены на гауссианы. У образца, облученного минимальной дозой ИИП $\left(8.4 \cdot 10^{5} \mathrm{~Gy}\right)$, интенсивность спектра РИОП оказалась очень малой, что затрудняет его анализ. Поэтому разложение этого спектра на гауссианы не производилось.

На рис. 2 представлены результаты разложения спектров РИОП на гауссианы. Видно, что спектры представляют собой суперпозицию четырех пиков. Параметры этих пиков (максимум энергии оптического поглощения $E_{\max }$ и полная ширина на половине высоты FWHM) представлены в табл. 1. Параметры компонент РИОП в целом близки к литературным данным [13,30], вследствие чего можно утверждать, что облучение ИИП $\mathrm{Fe}^{10+}$ приводит к образованию в кристалле $F$-центров (мак-

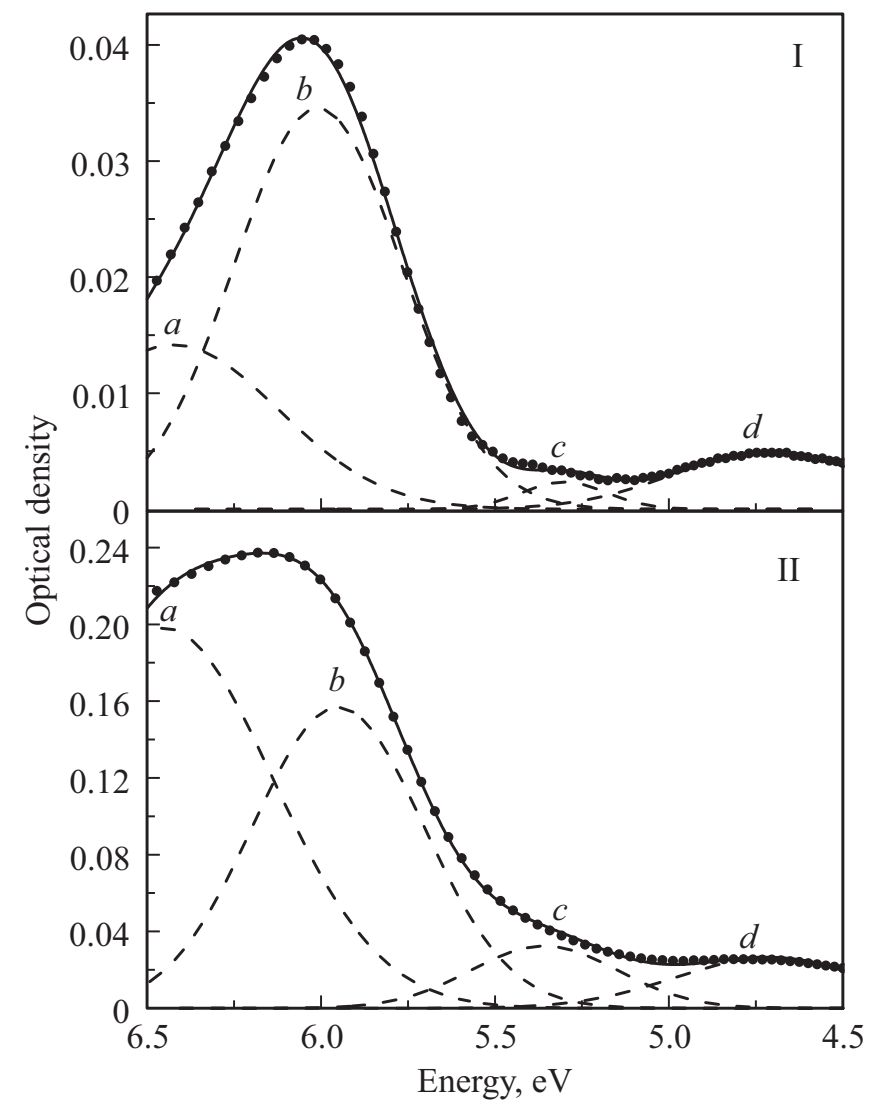

Рис. 2. РИОП кристаллов сапфира, облученных ИИП $\mathrm{Fe}^{10+} \mathrm{c}$ дозами $D_{2}=8.4 \cdot 10^{6} \mathrm{~Gy}$ (I) и $D_{3}=8.4 \cdot 10^{7} \mathrm{~Gy}(\mathrm{II})$. Штриховыми линиями показаны результаты разложения на гауссианы. 
Таблица 1. Параметры разложения спектров РИОП на гауссианы

\begin{tabular}{c|c|c|c|c|c}
\hline Пик & Параметр & $\begin{array}{c}\text { Доза } \\
8.4 \cdot 10^{6} \mathrm{~Gy}\end{array}$ & $\begin{array}{c}\text { Доза } \\
8.4 \cdot 10^{7} \mathrm{~Gy}\end{array}$ & $\begin{array}{c}\text { Литературные } \\
\text { данные [13,30] }]\end{array}$ & Центр \\
\hline \multirow{2}{*}{$a$} & $E_{\max }, \mathrm{eV}$ & 6.42 & 6.45 & 6.30 & \multirow{2}{*}{} \\
& FWHM, eV & 0.71 & 0.73 & 0.68 & $F^{+}$ \\
\hline \multirow{2}{*}{$b$} & $E_{\max }, \mathrm{eV}$ & 6.0 & 5.95 & 6.05 & \multirow{2}{*}{$F$} \\
& FWHM, eV & 0.57 & 0.58 & 0.67 & \\
\hline \multirow{2}{*}{$c$} & $E_{\max }, \mathrm{eV}$ & 5.30 & 5.36 & 5.41 & \multirow{2}{*}{$F^{+}$} \\
& FWHM, eV & 0.30 & 0.50 & 0.32 & \\
\hline \multirow{2}{*}{$d$} & $E_{\max }, \mathrm{eV}$ & 4.70 & 4.70 & 4.85 & \multirow{2}{*}{$F^{+}$} \\
& FWHM, eV & 0.65 & 0.65 & 0.41 &
\end{tabular}

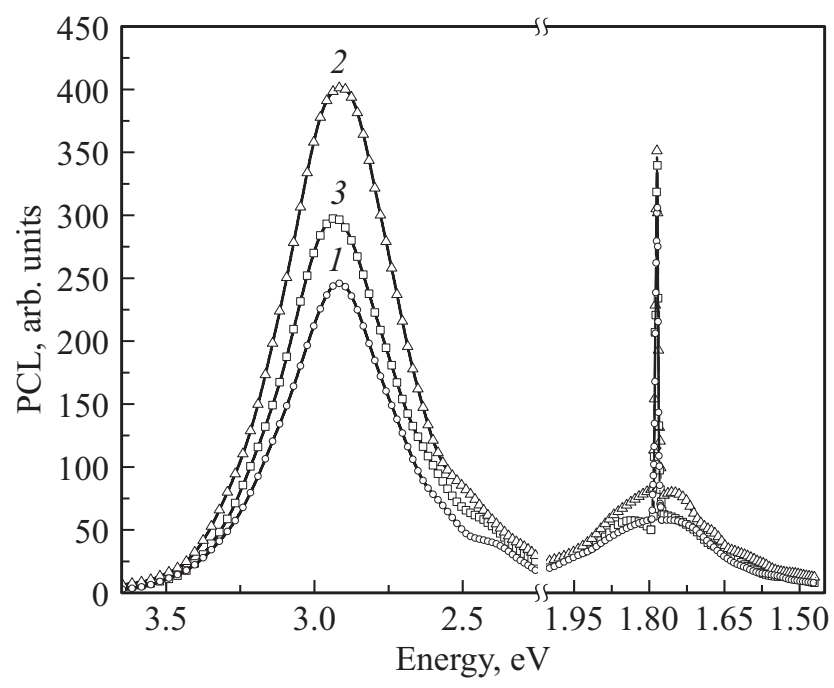

Pис. 3. Спектры ИКЛ монокристаллов сапфира, облученных ИИП $\mathrm{Fe}^{10+}$ дозами $D_{1}=8.4 \cdot 10^{5} \mathrm{~Gy}(1), D_{2}=8.4 \cdot 10^{6} \mathrm{~Gy}(2)$ и $D_{3}=8.4 \cdot 10^{7} \mathrm{~Gy}(3)$.

симум поглощения $6.0 \mathrm{eV}$ ) и $F^{+}$-центров (максимумы поглощения $6.42,5.35$ и $4.7 \mathrm{eV})$. Также из рис. 1 можно заметить резкое возрастание концентраций указанных центров по мере увеличения дозы ионного пучка $\mathrm{Fe}^{10+}$.

\section{2. Импульсная катодолюминесценция}

Известно, что метод ОП по сравнению с люминесцентными методами анализа (в том числе ИКЛ и ФЛ) является менее чувствительным. Так, например, в нашем случае трудно по ОП судить об образовании радиационно-индуцированных дефектов в образце сапфира, облученном наименьшей дозой ИИП $\left(8.4 \cdot 10^{5} \mathrm{~Gy}\right)$ (рис. 1). Для подтверждения образования центров $F$ типа в облученных монокристаллах сапфира была измерена ИКЛ. На рис. 3 представлены спектры ИКЛ, на которых присутствуют две полосы люминесценции. Первая полоса при $3 \mathrm{eV}$, согласно [12], соответствует полосе свечения $F$-центров. Стоит отметить, что ИКЛ в полосе $F$-центров происходит за счет процессов рекомбинации электронов с $F^{+}$-центрами. Таким образом, полоса ИКЛ при $3 \mathrm{eV}$ отражает наличие $F^{+}$-центров в облученных кристаллах. При этом наблюдается немонотонная зависимость интенсивности указанной полосы от величины дозы облучения монокристаллов сапфира. Вторая полоса при $1.8 \mathrm{eV}$ связана с примесью ионов $\mathrm{Cr}^{3+}$ в $\alpha-\mathrm{Al}_{2} \mathrm{O}_{3}[31,32]$.

\section{3. Фотолюминесценция}

Спектрометр КЛАВИ обеспечивает диапазон регистрации ИКЛ от 3.54 до $1.65 \mathrm{eV}(350-750 \mathrm{~nm})$. Поэтому он не позволяет регистрировать люминесценцию $F^{+}$центров, имеющих максимум свечения при $3.8 \mathrm{eV}$. Для подтверждения образования $F^{+}$-центров в $\alpha-\mathrm{Al}_{2} \mathrm{O}_{3}$ при облучении ИИП дополнительно была измерена ФЛ. На рис. 4, $a$ представлены спектры возбуждения ФЛ в полосе $F^{+}$-центров $(3.8 \mathrm{eV})$ исходных и облученных разными дозами образцов сапфира. Видно, что спектры возбуждения полосы при $3.8 \mathrm{eV}$ содержат две полосы при 5.2 и $4.7 \mathrm{eV}$, которые, согласно статье [33], идентифицируется как полосы возбуждения $F^{+}$-центров. При возбуждении в полосе $5.2 \mathrm{eV}$ (рис. $4, b$ ) наблюдается максимум свечения ФЛ при $3.8 \mathrm{eV}$, который связан с люминесценцией $F^{+}$-центра [13].

Из рис. 4 видно также, что интенсивность ФЛ $F^{+}$центров монокристаллов сапфира увеличивается с ростом дозы облучения до величины $8.4 \cdot 10^{6} \mathrm{~Gy}$, а при большей дозе падает, что коррелирует с результатами измерения ИКЛ (рис. 3). Падение интенсивности ФЛ при высоких дозах может быть обусловлено концентрационным тушением люминесценции. При этом роль тушителей могут играть внедряющиеся в $\alpha-\mathrm{Al}_{2} \mathrm{O}_{3}$ при облучении ИИП ионы железа. С увеличением концентрации

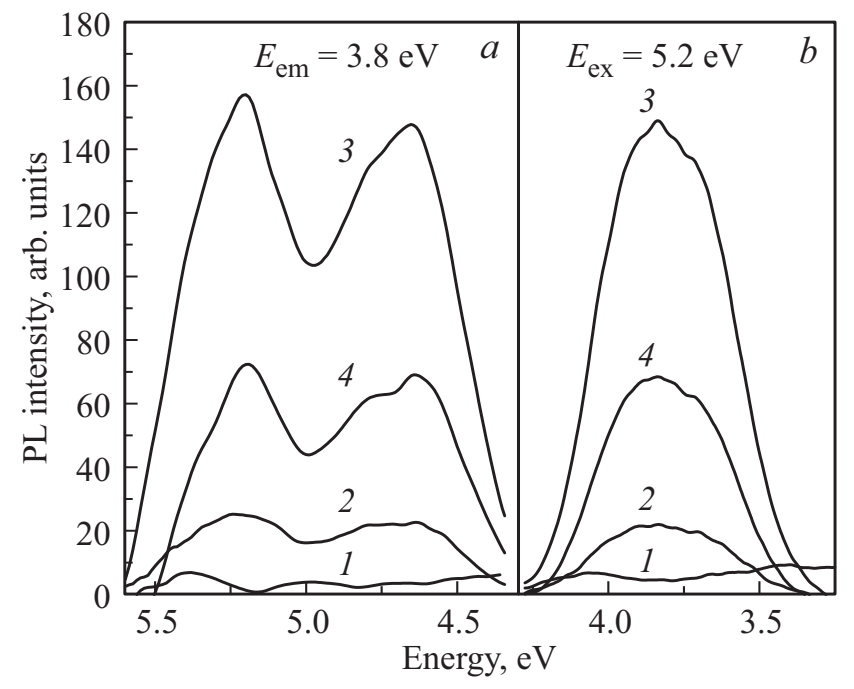

Рис. 4. Спектры возбуждения (a) и свечения (b) ФЛ $F^{+}$центров исходных монокристаллов сапфира (1) и кристаллов, облученных ИИП $\mathrm{Fe}^{10+}$ дозами $D_{1}=8.4 \cdot 10^{5} \mathrm{~Gy}(2)$, $D_{2}=8.4 \cdot 10^{6}$ Gy $(3), D_{3}=8.4 \cdot 10^{7}$ Gy $(4)$. 

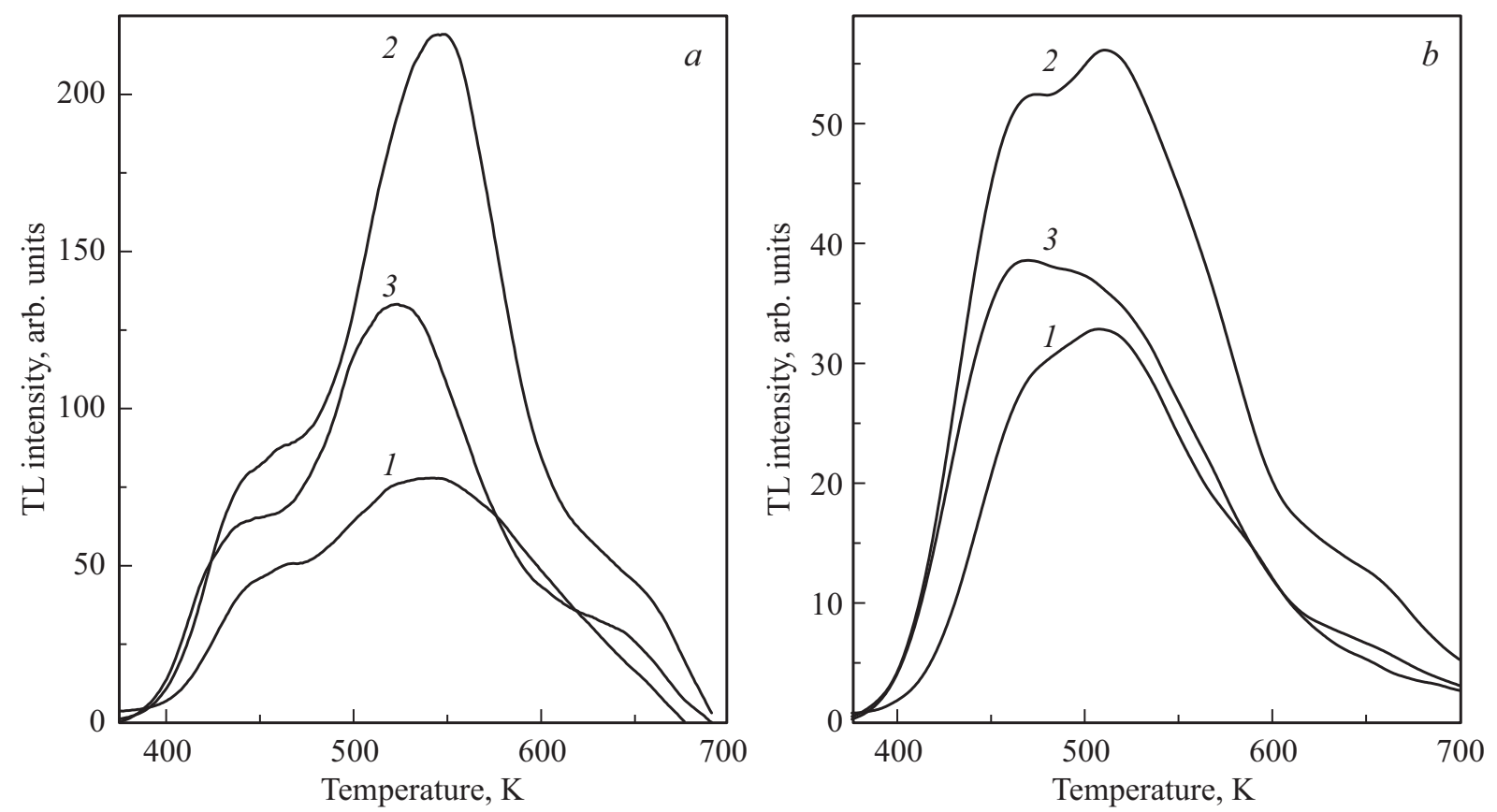

Рис. 5. Измеренные в спектральном диапазоне $200-650 \mathrm{~nm}(a)$ и 200-365 nm (b) спектры ТЛ образцов сапфира, облученных ИИП $\mathrm{Fe}^{10+}$ дозами $D_{1}=8.4 \cdot 10^{5} \mathrm{~Gy}(1), D_{2}=8.4 \cdot 10^{6} \mathrm{~Gy}(2), D_{3}=8.4 \cdot 10^{7} \mathrm{~Gy}(3)$.

радиационно-индуцированных центров $F$-типа и ионов железа в $\alpha-\mathrm{Al}_{2} \mathrm{O}_{3}$ происходит уменьшение расстояния между данными центрами, вследствие чего становится возможным перенос энергии возбуждения от центра к центру. При перехвате переносимой энергии ионами железа последние релаксируют в основное состояние безызлучательно, действуя как тушители люминесценции. Подробно механизмы тушения люминесценции ионами железа обсуждаются в работах [34,35].

\section{4. Термолюминесценция}

Дальнейшим этапом исследований являлось измерение ТЛ для выявления радиационно-индуцированных дефектов в сапфире, являющихся ловушками носителей заряда. Изучение ТЛ облученных образцов сапфира также интересно с точки зрения возможности их применения в радиационной дозиметрии импульсных ионных пучков. Измерения производились с использованием ФЭУ-130 и $Ф Э У-142$ в спектральных диапазонах соответственно 200-650 nm и 200-365 nm. Согласно [36], максимум люминесценции $F$-центров располагается при $415 \mathrm{~nm}$, а $F^{+}$-центров - при $330 \mathrm{~nm}$. Таким образом, при измерении ТЛ с использованием ФЭУ-130 будет регистрироваться свечение $F$ - и $F^{+}$-центров, а при использовании ФЭУ-142 - только $F^{+}$-центров.

Результаты представлены на рис. 5. Данные рисунка показывают, что облучение ИИП монокристаллов сапфира приводит к возникновению ТЛ в кристалле при $T=350-750 \mathrm{~K}$, что свидетельствует об образовании радиационно-индуцированных центров захвата при импульсном ионном облучении. При этом интенсивность ТЛ для обоих спектральных диапазонов немонотонно зависит от величины дозы облучения: растет до $8.4 \cdot 10^{6} \mathrm{~Gy}$, а затем падает. Аналогичная зависимость интенсивности люминесценции от дозы наблюдалась и в спектрах ИКЛ и ФЛ. Можно предположить, что падение интенсивности ТЛ при наибольшей дозе облучения связано с концентрационным тушением люминесценции. Полученный результат коррелирует с результатами измерения ИКЛ для $F$-центров и ФЛ для $F^{+}$-центров.

Из рис. 5 видно также, что кривые ТЛ имеют сложную форму и, вероятно, состоят из нескольких элементарных пиков. Для определения кинетических параметров пиков, несущих информацию о ловушках, образуемых в $\alpha$ $\mathrm{Al}_{2} \mathrm{O}_{3}$ под действием ИИП, кривые ТЛ рис. 5 были разложены на элементарные составляющие согласно уравнению ТЛ общего порядка кинетики [37]:

$$
\begin{aligned}
I(T)= & I_{m} b^{\frac{b}{b-1}} \exp \left(\frac{E}{k T} \frac{T-T_{m}}{T_{m}}\right)\left[(b-1)(1-\Delta) \frac{T^{2}}{T_{m}^{2}}\right. \\
& \left.\times \exp \left(\frac{E}{k T} \frac{T-T_{m}}{T_{m}}\right)+Z_{m}\right]^{-\frac{b}{b-1}},
\end{aligned}
$$

где $I(T)$ - интенсивность ТЛ, $T$ - температура $(\mathrm{K})$, $k$ - постоянная Больцмана, $b-$ порядок кинетики, $E$ - энергия активации $(\mathrm{eV}), T_{m}$ - температура максимума $(\mathrm{K}), I_{m}$ - интенсивность максимума; $\Delta=2 k T / E, \Delta_{m}=2 k T_{m} / E, Z_{m}=1+(b-1) \Delta_{m}$. Величины $b, E, T_{m}$ и $I_{m}$ являлись варьируемыми параметрами уравнения (2). Значения частотного фактора $S\left(\mathbf{s}^{-1}\right)$ 
Таблица 2. Кинетические параметры пиков ТЛ, измеренной в разных спектральных диапазонах

\begin{tabular}{|c|c|c|c|c|c|c|c|}
\hline \multirow{2}{*}{ Пик } & \multirow{2}{*}{ Параметр } & \multicolumn{3}{|c|}{ ТЛ в спектральном диапазоне 200-650 nm } & \multicolumn{3}{|c|}{ ТЛ в спектральном диапазоне 200-365 nm } \\
\hline & & $8.4 \cdot 10^{5} \mathrm{~Gy}$ & $8.4 \cdot 10^{6} \mathrm{~Gy}$ & $8.4 \cdot 10^{7} \mathrm{~Gy}$ & $8.4 \cdot 10^{5} \mathrm{~Gy}$ & $8.4 \cdot 10^{6} \mathrm{~Gy}$ & $8.4 \cdot 10^{7} \mathrm{~Gy}$ \\
\hline$A$ & $\begin{array}{c}E, \mathrm{eV} \\
S, 10^{10} \cdot \mathrm{s}^{-1} \\
T_{m}, \mathrm{~K} \\
B\end{array}$ & $\begin{array}{c}0.97 \\
1.03 \\
447 \\
2.0\end{array}$ & $\begin{array}{c}0.97 \\
1.05 \\
446 \\
2.0\end{array}$ & $\begin{array}{c}0.97 \\
1.03 \\
439 \\
2.0\end{array}$ & $\begin{array}{c}0.99 \\
1.04 \\
454 \\
1.9\end{array}$ & $\begin{array}{l}0.99 \\
1.08 \\
454 \\
2.0\end{array}$ & $\begin{array}{c}0.98 \\
1.04 \\
449 \\
2.0\end{array}$ \\
\hline$B$ & $\begin{array}{c}E, \mathrm{eV} \\
S, 10^{10} \cdot \mathrm{s}^{-1} \\
T_{m}, \mathrm{~K} \\
B\end{array}$ & $\begin{array}{l}1.11 \\
1.61 \\
498 \\
2.0\end{array}$ & $\begin{array}{c}1.12 \\
1.64 \\
502 \\
2.0\end{array}$ & $\begin{array}{c}1.12 \\
1.90 \\
500 \\
2.0\end{array}$ & $\begin{array}{c}1.089 \\
1.79 \\
487 \\
2.0\end{array}$ & $\begin{array}{c}1.11 \\
1.45 \\
500 \\
2.0\end{array}$ & $\begin{array}{c}1.1 \\
1.95 \\
490 \\
2.0\end{array}$ \\
\hline C & $\begin{array}{c}E, \mathrm{eV} \\
S, 10^{10} \cdot \mathrm{s}^{-1} \\
T_{m}, \mathrm{~K} \\
B\end{array}$ & $\begin{array}{c}1.22 \\
2.32 \\
539 \\
1.9\end{array}$ & $\begin{array}{c}1.22 \\
2.24 \\
539 \\
1.9\end{array}$ & $\begin{array}{c}1.22 \\
3.81 \\
535 \\
1.9\end{array}$ & $\begin{array}{c}1.20 \\
2.97 \\
526 \\
1.8\end{array}$ & $\begin{array}{c}1.21 \\
2.38 \\
534 \\
1.8\end{array}$ & $\begin{array}{c}1.22 \\
3.64 \\
530 \\
1.9\end{array}$ \\
\hline$D$ & $\begin{array}{c}E, \mathrm{eV} \\
S, 10^{10} \cdot \mathrm{s}^{-1} \\
T_{m}, \mathrm{~K} \\
B\end{array}$ & $\begin{array}{c}1.33 \\
3.30 \\
581 \\
1.7\end{array}$ & $\begin{array}{c}1.32 \\
4.87 \\
565 \\
1.9\end{array}$ & $\begin{array}{c}1.33 \\
3.37 \\
580 \\
1.7\end{array}$ & $\begin{array}{l}1.34 \\
3.85 \\
579 \\
2.0\end{array}$ & $\begin{array}{l}1.34 \\
4.87 \\
575 \\
2.0\end{array}$ & $\begin{array}{c}1.34 \\
4.87 \\
575 \\
2.0\end{array}$ \\
\hline E & $\begin{array}{c}E, \mathrm{eV} \\
S, 10^{10} \cdot \mathrm{s}^{-1} \\
T_{m}, \mathrm{~K} \\
B\end{array}$ & $\begin{array}{c}1.5 \\
9.10 \\
629 \\
1.3\end{array}$ & $\begin{array}{c}1.51 \\
6.30 \\
641 \\
1.3\end{array}$ & $\begin{array}{c}1.50 \\
7.07 \\
637 \\
1.3\end{array}$ & $\begin{array}{c}1.50 \\
6.77 \\
637 \\
1.6\end{array}$ & $\begin{array}{c}1.53 \\
7.82 \\
643 \\
1.6\end{array}$ & $\begin{array}{c}1.51 \\
5.97 \\
642 \\
1.6\end{array}$ \\
\hline$G$ & $\begin{array}{c}E, \mathrm{eV} \\
S, 10^{10} \cdot \mathrm{s}^{-1} \\
T_{m}, \mathrm{~K} \\
B\end{array}$ & - & - & - & $\begin{array}{c}1.68 \\
1.35 \\
694 \\
1.9\end{array}$ & $\begin{array}{c}1.68 \\
1.18 \\
697 \\
1.9\end{array}$ & $\begin{array}{c}1.68 \\
1.10 \\
699 \\
1.9\end{array}$ \\
\hline & $\mathrm{M}, \%$ & 1.93 & 1.35 & 1.23 & 2.67 & 2.05 & 1.88 \\
\hline
\end{tabular}

вычислялись по формуле [37]:

$$
S=\frac{\beta E}{k T_{m}^{2}} \frac{1}{Z_{m}} \exp \left(\frac{E}{k T_{m}}\right),
$$

где $\beta$ - скорость нагрева $(\mathrm{K} / \mathrm{s})$. Результаты разложения кривых ТЛ представлены на рис. 6 и 7. Кинетические параметры обнаруженных пиков приведены в табл. 2. Для определения точности разложения кривых ТЛ рассчитывался FOM-фактор по формуле [38]:

$$
\mathrm{FOM}=\frac{\Sigma_{i}\left|I_{\exp }\left(T_{i}\right)-I_{\mathrm{fit}}\left(T_{i}\right)\right|}{\Sigma_{i} I_{\exp }\left(T_{i}\right)} \cdot 100 \%,
$$

где $I_{\text {exp }}\left(T_{i}\right)$ - множество действительных значений интенсивности кривой ТЛ, полученных экспериментальным путем, $I_{\mathrm{fit}}\left(T_{i}\right)$ - множество значений интенсивности кривой ТЛ, полученных теоретически при разложении на компоненты. Расчет показал, что значения FOMфактора не превышают 5\%, что говорит о достаточной корректности и точности проведенного разложения.

Анализ рис. 6 и 7 и табл. 2 показывает, что при разложении на компоненты кривых ТЛ в спектральном диапазоне 200-650 nm было получено 5 элементарных пиков, а в диапазоне $200-365 \mathrm{~nm}-6$. По данным табл. 2 видно, что большинство пиков имеют близкий ко второму порядок кинетики ТЛ, что свидетельствует об интенсивных процессах повторного захвата свободных носителей заряда в ловушки при термостимуляции. Энергия активации $(E)$ и частотный фактор $(S)$ имеют типичные значения для ТЛ широкозонных диэлектриков в интервале температур 350-750 K [39-42].

Из рис. 6 и 7 видно, что в температурном интервале от 350 до $700 \mathrm{~K}$ наблюдаются одинаковые по температурному положению пики ТЛ в обоих спектральных диапазонах (пики $A, B, C, D$ и $E$ ). Известно, что в оксиде алюминия ТЛ в полосе $F$-центров может быть связано с рекомбинацией электрона, освобожденного из электронной ловушки, с $F^{+}$-центром согласно реакции [43]

$$
F^{+}+\bar{e}=F^{*}+h v(415 \mathrm{~nm}) .
$$

ТЛ в полосе $F^{+}$-центров связана с рекомбинацией дырки, освобожденной из дырочной ловушки, с $F$-центром согласно реакции [43]

$$
F+h^{+}=F^{+*}+h v(330 \mathrm{~nm}) .
$$




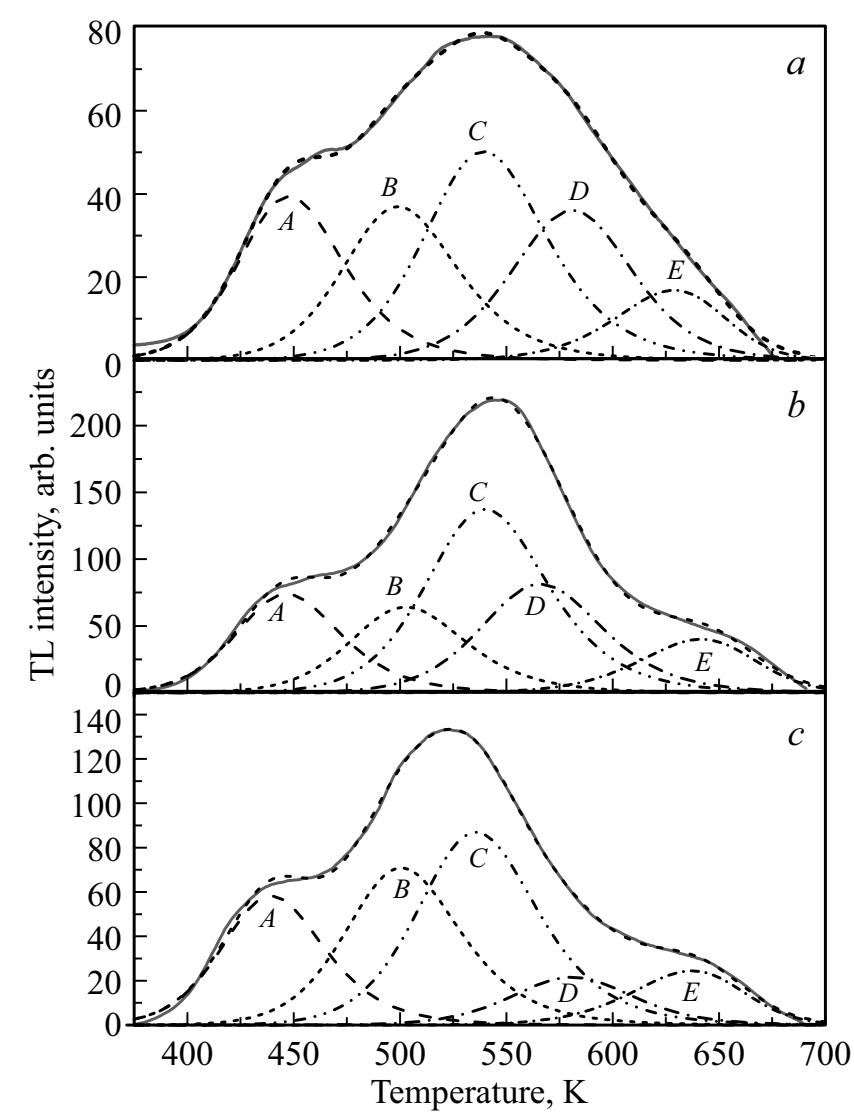

Рис. 6. Результаты разложения спектров ТЛ образцов, облученных дозами $D_{1}=8.4 \cdot 10^{5} \mathrm{~Gy}(a), D_{2}=8.4 \cdot 10^{6} \mathrm{~Gy}(b)$ и $D_{3}=8.4 \cdot 10^{7} \mathrm{~Gy}(c)$, на гауссовы полосы $A-E$.

Из табл. 2 видно, что в пределах погрешности наблюдается близость значений кинетических параметров ловушек, обусловливающих пики ТЛ, имеющие одинаковое температурное положение в двух рассматриваемых спектральных диапазонах. Указанный результат свидетельствует о том, что центры захвата, ответственные за ТЛ, регистрируемую с помощью двух разных ФЭУ, имеют одну и ту же физическую природу. Учитывая, что $Ф Э У-130$ регистрирует свечение $F$ - и $F^{+}$-центров, а ФЭУ-142 - только $F^{+}$-центров, можно предположить, что в облученных образцах доминирующими центрами свечения ТЛ являются $F^{+}$-центры, а ловушки имеют дырочную природу, что согласуется с реакцией (6).

Согласно рис. 6, наибольший вклад в ТЛ сапфира в спектральном диапазоне 200-650 nm при всех дозах облучения вносит ловушка $C$, а наименьший - ловушка $E$. В данном спектральном диапазоне ТЛ при наименьшей дозе облучения интенсивность ТЛ ловушек $A, B$ и $D$ почти одинакова, но с увеличением дозы облучения ИИП $\mathrm{Fe}^{10+}$ происходит неравномерное перераспределение относительного вклада указанных ловушек в ТЛ. Так, при увеличении дозы обучения от $8.4 \cdot 10^{5}$ до $8.4 \cdot 10^{6} \mathrm{~Gy}$ происходит увеличение интенсивностей всех элементарных пиков ТЛ. Дальнейшее увеличение дозы облучения приводит к росту интенсивности ТЛ только для пика, связанного с ловушкой $B$, в то время как интенсивность всех остальных пиков падает.

Из рис. 7 видно, что наибольший вклад в интенсивность ТЛ в спектральном диапазоне $200-365 \mathrm{~nm}$ при дозе облучения $8.4 \cdot 10^{5} \mathrm{~Gy}$ вносит ловушка, связанная с пиком $C$. При дальнейшем повышении дозы облучения до $8.4 \cdot 10^{6}$ Gy наблюдается рост интенсивности ТЛ всех пиков, наиболее чувствительной к увеличению дозы оказалась ловушка $A$, интенсивность максимума ТЛ которой увеличивается в 4 раза. При повышении дозы облучения до $8.4 \cdot 10^{7} \mathrm{~Gy}$ происходит падение интенсивности ТЛ всех компонент, причем их относительный вклад в ТЛ практически не меняется. Установление точного вида зависимости интенсивности ТЛ различных компонент от дозы требует дальнейших более детальных исследований. При этом наличие диапазона доз, в котором наблюдается рост интенсивности ТЛ, позволяет рассматривать монокристаллический сапфир как перспективный материал для ТЛ-дозиметрии используемых в работе ИИП $\mathrm{Fe}^{10+}$.

Нами был проведен сравнительный анализ температурного положения полученных компонент ТЛ с литературными данными. Так, ловушка $A$ характеризуется пиком при $450 \mathrm{~K}$, который принято считать дозиметрическим пиком в анион-дефектных кристаллах $\alpha-\mathrm{Al}_{2} \mathrm{O}_{3}$,

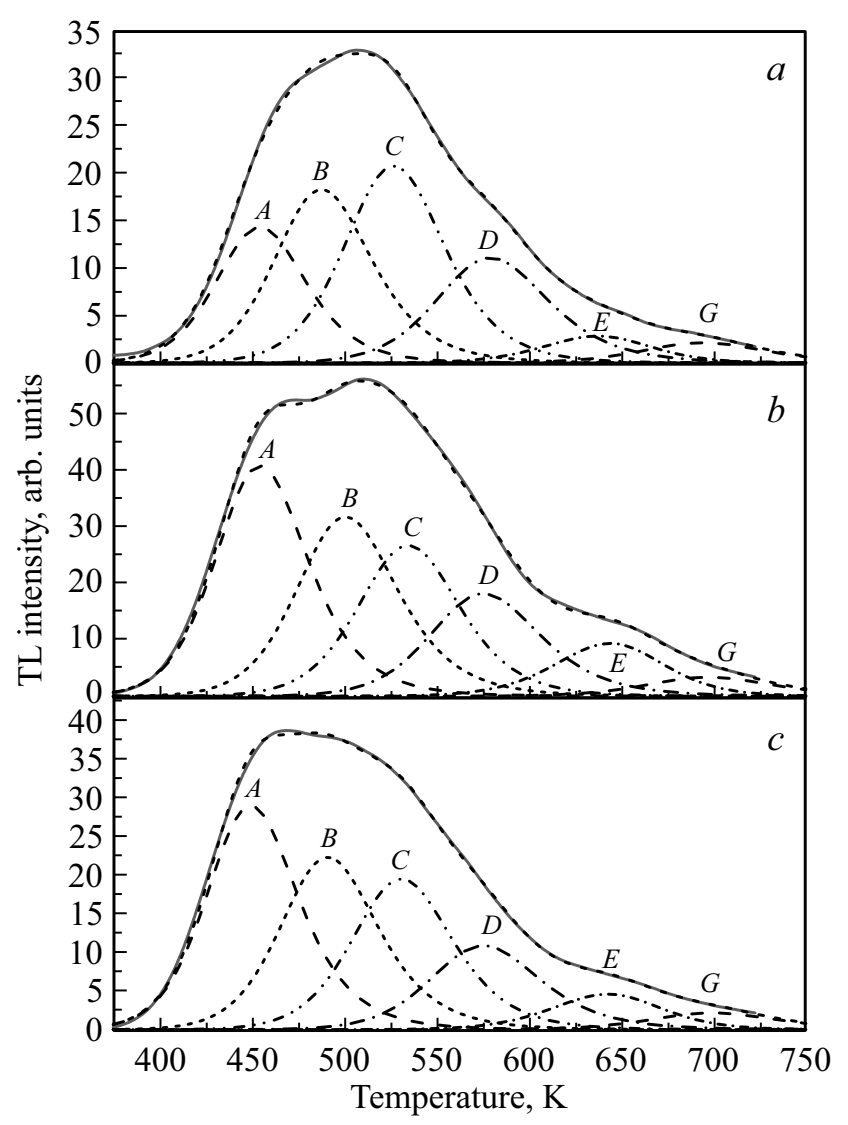

Рис. 7. Результаты разложения спектров ТЛ образцов, облученных дозами $D_{1}=8.4 \cdot 10^{5} \mathrm{~Gy}(a), D_{2}=8.4 \cdot 10^{6} \mathrm{~Gy}(b)$ и $D_{3}=8.4 \cdot 10^{7} \mathrm{~Gy}(c)$, на гауссовы полосы $A-G$. 
используемых в ТЛ-дозиметрии (коммерческий детектор ТЛД-500K) [44]. В этих же кристаллах, предварительно облученных дозой $3 \mathrm{~Gy} \beta$-излучения, в температурном диапазоне от 373 до $623 \mathrm{~K}$ при скорости нагрева $2 \mathrm{~K} / \mathrm{s}$ наблюдались два пика ТЛ [45]. По значениям температуры максимума $\left(T_{m}\right)$ и кинетических параметров $(E$ и $S)$ ловушки, ответственные за эти пики, схожи с ловушками $B$ и $D$ нашего разложения (рис. 6,7$)$. В статье $[46]$ в интервале температур от 425 до $500 \mathrm{~K}$ наблюдался интенсивный пик ТЛ $\left(T_{m} \approx 490 \mathrm{~K}\right.$, при скорости нагрева $\left.2 \mathrm{~K} / \mathrm{s}\right)$ в $\alpha-\mathrm{Al}_{2} \mathrm{O}_{3}: \mathrm{Ti}$, облученного дозой $2 \mathrm{kGy}$ сильноточного импульсного электронного пучка $(130 \mathrm{keV})$. Данный пик авторы [46] относят к центрам захвата, связанными с примесью ионов $\mathrm{Ti}^{3+}$, и он также близок по температурному положению с ТЛ-пиком ловушки $B$. В статье [47] при исследовании ТЛ анион-дефектных монокристаллов $\alpha-\mathrm{Al}_{2} \mathrm{O}_{3}$ (скорость нагрева $2 \mathrm{~K} / \mathrm{s}$ ), облученных импульсным электронным пучком $(130 \mathrm{keV})$, наблюдали пик с $T_{m}=575 \mathrm{~K}$, близкий к пику ловушки $D$ (табл. 2). Авторы статьи выдвигают предположение, что этот пик связан с перезарядкой ионов хрома в $\mathrm{Al}_{2} \mathrm{O}_{3}$. При этом он может содержать как дырочные, так и электронные компоненты, что согласуется с нашими результатами. В работе [47] также наблюдался сложный широкий ТЛпик с $T_{m}=700 \mathrm{~K}$, сопоставимый с ловушкой $G$ (табл. 2). Указанный пик ТЛ относят к глубокой ловушке в $\alpha$ $\mathrm{Al}_{2} \mathrm{O}_{3}$, причем в указанном пике наблюдался эффект разгорания ТЛ [47].

\section{Заключение}

По результатам работы можно сделать следующие выводы.

1) Методами люминесцентной и оптической спектроскопии доказано формирование радиационноиндуцированных дефектов $F$-типа в монокристаллах сапфира после их облучения ИИП $\mathrm{Fe}^{10+}(200 \mathrm{keV})$. Согласно результатам измерения ОП, концентрация данных центров растет по мере увеличения дозы ИИП от $8.4 \cdot 10^{5}$ до $8.4 \cdot 10^{7} \mathrm{~Gy}$.

2) По результатам измерения ИКЛ, ФЛ и ТЛ установлена немонотонная дозовая зависимость интенсивности люминесценции, что связано с ее концентрационным тушением. При этом центрами тушения могут являться ионы железа, имплантируемые в решетку облученных монокристаллов $\alpha-\mathrm{Al}_{2} \mathrm{O}_{3}$.

3) При разложении кривых ТЛ на элементарные компоненты с использованием уравнения общего порядка кинетики было получено 5 пиков в спектральном диапазоне $200-650 \mathrm{~nm}$ (где излучают $F$ и $F^{+}$-центры) и 6 пиков в диапазоне $200-365 \mathrm{~nm}$ (где люминесцируют только $F^{+}$-центры). Наблюдаемая близость значений кинетических параметров ТЛ, измеренной с помощью двух различных ФЭУ, может свидетельствовать об общности природы ловушек, ответственных за ТЛ, регистрируемой в различных спектральных диапазонах. Вклад рассмотренных ловушек в общую интенсивность ТЛ неодинаков и сильно зависит от величины дозы облучения. Большинство элементарных пиков имеют близкий ко второму порядок кинетики ТЛ, что свидетельствует об интенсивных процессах повторного захвата носителей заряда в ловушки. Высказано предположение, что в облученных ИИП монокристаллах сапфира ТЛ обусловлена главным образом свечением $F^{+}$-центров. Точная идентификация природы центров свечения, ответственных за ТЛ исследуемых кристаллов, требует проведения дополнительных исследований путем измерения ТЛ со спектральным разрешением.

4) Существование зависимости интенсивности ТЛ от дозы ИИП позволяет рассматривать монокристаллический $\alpha-\mathrm{Al}_{2} \mathrm{O}_{3}$ как возможный материал для разработки люминесцентных детекторов высокодозных импульсных ионных излучений. Для решения этой задачи необходимо установить точный вид дозовых характеристик ТЛ различных компонент, используя большее количество значений поглощенных доз ИИП.

\section{Благодарности}

Выражаем благодарность научной лаборатории ФТИ УрФУ „Физика функциональных материалов углеродной микро- и оптоэлектроники“ за предоставление оборудования для измерения ФЛ и ОП.

\section{Финансирование работы}

Исследование выполнено в рамках инициативного научного проекта FEUZ-2020-0059 Минобрнауки РФ.

\section{Конфликт интересов}

Авторы заявляют, что у них нет конфликта интересов.

\section{Список литературы}

[1] Dobrovinskaya E.R., Lytvynov L.A., Pishchik V. Sapphire: Material, Manufacturing, Applications. Springer Science and Business Media, 2009. 481 p.

[2] Capper P. Bulk Crystal Growth of Electronic, Optical and Optoelectronic Materials. John Wiley and Sons, 2005. V. 14. $541 \mathrm{p}$.

[3] Shikama T., Yasuda K., Yamamoto S., Kinoshita C., Zinkle S.J., Hodgson E.R. // J. Nucl. Mater. 1999. V. 271. P. 560. doi 10.1016/S0022-3115(98)00872-1

[4] Швари, К.К. Диэлектрические материалы: Радиационные процессы и радиационная стойкость. Рига: Зинатне, 1989. $187 \mathrm{c}$.

[5] Kruzhalov A.V., Mil'man I.I., Neshev F.G., Revkov I.G. // Technical Physics Letters. 2008. V. 34. N 9. P. 809. doi 10.1134/S1063785008090289

[6] Shablonin E., Popov A.I., Prieditis G., Vasil'chenko E., Lushchik A. // J. Nucl. Mater. 2021. V. 543. P. 152600. doi 10.1016/j.jnucmat.2020.152600 
[7] Izerrouken M., Djouadi Y., Zirour H. // Nucl. Instrum. Methods Phys. Res. 2014. V. 319. P. 29. doi 10.1016/j.nimb.2013.11.009

[8] Popov A.I. Lushchik A., Shablonin E., Vasil'chenko E., Kotomin E.A., Moskina A.M., Kuzovkov V.N. // Nucl. Instrum. Methods Phys. Res. 2018. V. 433. P. 93. doi 10.1016/j.nimb.2018.07.036

[9] Zinkle S.J., Kinoshita C. // J. Nucl. Mater. 1997. V. 251. P. 200. doi 10.1016/S0022-3115(97)00224-9

[10] Kotomin E.A., Popov A.I. // Nucl. Instrum. Methods Phys. Res. 1998. V. 141. P. 1. doi 10.1016/S0168-583X(98)00079-2

[11] Weber W.J., Ewing R.C., Catlow C.R.A., De La Rubia T.D., Hobbs L.W., Kinoshita C., Zinkle S.J. et al. // JMR. 1998. V. 13. P. 1434.

[12] Lee K.H., Crawford J.H., Jr. // Phys. Rev. 1979. V. 19. N 6. P. 3217. doi 10.1103/PhysRevB.19.3217

[13] Evans B.D., Stapelbroek M. // Phys. Rev. 1978. V. 18. N 12. P. 7089. doi 10.1103/PhysRevB.18.7089

[14] Atobe K., Nishimoto N., Nakagawa M. // Phys. Status Solidi. 1985. V. 89. N 1. P. 155. doi 10.1002/pssa.2210890115

[15] Mohanty T., Mishra N.C., Singh F., Bhat S.V., Kanjilal D. // Radiat. Meas. 2003. V. 36. N 1-6. P. 723. doi 10.1016/S13504487(03)00234-8

[16] Aono K., Toida H., Terashima K., Iwaki M. // Nucl. Instrum. Methods Phys. Res. 2001. V. 175. P. 580. doi 10.1016/S0168583X $(00) 00648-0$

[17] Al Ghamdi A., Townsend P.D. // Nucl. Instrum. Methods Phys. Res. 1990. V. 46. N 1-4. P. 133. doi 10.1016/0168583X(90)90684-M

[18] Пушкарев А.И., Исакова Ю.И. Диагностика мощных ионных пучков: монография. Новосибирск: Изд. АНС „СибАК“, 2016. 126 с.

[19] Toshima R., Miyamaru H., Asahara J., Murasawa T., Takahashi A. // J. Nucl. Sci. Technol. 2002. V. 39. N 1. P. 15. doi 10.1080/18811248.2002.9715152

[20] Ананченко Д.В., Никифоров С.В., Рамазанова Г.Р., Баталов Р.И., Баязитов Р.М., Новиков Х.А. // Опт. и спектр. 2020. T. 128. № 2. C. 211. doi 10.21883/0000000000; Ananchenko D.V., Nikiforov S.V., Ramazanova G.R., Batalov R.I., Bayazitov R.M., Novikov H.A. // Opt. Spectrosc. 2020. V. 128. N 2. P. 207. doi 10.1134/S0030400X20020022

[21] Ananchenko D.V., Nikiforov S.V., Kuzovkov V.N., Popov A.I., Ramazanova G.R., Batalov R.I., Bayazitov R.M., Novikov H.A. // Nucl. Instrum. Methods Phys. Res. 2020. V. 466. P. 1. doi 10.1016/j.nimb.2019.12.032

[22] Chen Y., Abraham M.M., Pedraza D.F. // Nucl. Instrum. Methods Phys. Res. 1991. V. 59. P. 1163. doi 10.1016/0168583X(91)95786-D

[23] Song Y. et al. // Nucl. Instrum. Methods Phys. Res. 2007. V. 254. N 2. P. 268. doi 10.1016/j.nimb.2006.11.058

[24] Sandlin G.D. // Astrophys. J. 1979. V. 227. P. L107.

[25] Марков Н.В., Бахмутова А.В., Голубев А.А., Канцырев А.В., Лукьяшин В.Е., Рудской И.В., Смирнов Г.Н., Фертман А.Д., Худомясов А.В. // ПТЭ. 2014. T. 57. № 1. C. 55. doi 10.7868/S003281621401008X; Markov N.V., Bakhmutova A.V., Golubev A.A., Kantsyrev A.V., Luckjashin V.E., Rudskoi I.V., Smirnov G.N., Fertman A.D., Khudomyasov A.V. // INET. 2014. V. 57. N 1. P. 55. doi 10.1134/S0020441214010084

[26] Ziegler J.F., Ziegler M.D., Biersack J.P. // Nucl. Instrum. Methods Phys. Res. 2010. V. 268. N 11-12. P. 1818. doi 10.1016/j.nimb.2010.02.091
[27] Lambda 25, 35, 45 User's Guide: Manual. United Kingdom, 2000. 114 p.

[28] Соломонов В.И., Липчак А.И., Михайлов С.Г. // Аналитика и контроль. 1998. № 1. С. 8.

[29] Perkin Elmer LS 55 User's Guide: Manual. United Kingdom, 2007. 169 p.

[30] Вайнштейн И.А., Кортов В.С. // ФТТ. 2000. Т. 42. № 7. C. 1223.; Vainshtein I.A., Kortov V.S. // Phys. Solid State. 2000. V. 42. N 7. P. 1259

[31] Ghamnia M., Jardin C., Bouslama M. // J. Electron. Spectrosc. Relat. Phenom. 2003. V. 133. N 1-3. P. 55. doi 10.1016/j.elspec.2003.08.003

[32] Алукер Н.Л., Винникова Е.А. // Вестник КемГУ. 2008. № 2. P. 214.

[33] Evans B.D., Pogatshnik G.J., Chen Y. // Nucl. Instrum. Methods Phys. Res. 1994. V. 91. N 1-4. P. 258. doi 10.1016/0168-583X(94)96227-8

[34] Tabei M., Shionoya S., Ohmatsu H. // Jpn. J. Appl. Phys. 1975. V. 14. N 2. P. 240.

[35] Del Nery S.M., Pontuschka W.M., Isotani S., Rouse C.G. // Phys. Rev. 1994. V. 49. N 6. P. 3760. doi 10.1103/PhysRevB.49.3760

[36] Itou M., Fujiwara A., Uchino T. // J. Phys. Chem. C. 2009. V. 113. N 49. P. 20949. doi $10.1021 / \mathrm{jp} 908417 \mathrm{~m}$

[37] Kitis G., Gomez-Ros J.M., Tuyn J.W.N. // J. Phys. D: Appl. Phys. 1998. V. 31. N 19. P. 2636.

[38] Balian H.G., Eddy N.W. // Nucl. Instrum. Methods Phys. Res. 1977. V. 145. N 2. P. 389. doi 10.1016/0029-554X(77)90437-2

[39] Lokesha H.S., Chithambo M.L., Chikwembani S. // J. Lumin. 2020. V. 218. P. 116864. doi 10.1016/j.jlumin.2019.116864

[40] Ogorodnikov I.N., Kruzhalov A.V., Kuznetsov A.Y. // Radiat. Prot. Dosim. 1996. V. 65. N 1-4. P. 109. doi 10.1093/oxfordjournals.rpd.a031599

[41] Aşlar E., Şahiner E., Polymeris G.S., Meriç N. // Appl. Radiat. Isot. 2017. V. 129. P. 142. doi 10.1016/j.apradiso.2017.08.026

[42] Кортов В.С., Мильман И.И., Никифоров С.В. // ФТТ. 1997. T. 39. № 9. C. 1538.

[43] McKeever S.W.S., Akselrod M.S., Colyott L.E., Agersnap Larsen N., Polf J.C., Whitley V. // Radiat. Prot. Dosim. 1999. V. 84. N 1-4. P. 163.

[44] Akselrod M.S., Kortov V.S., Kravetsky D.J., Gotlib V.I. // Radiat. Prot. Dosim. 1990. V. 32. N 1. P. 15.

[45] Chithambo M.L., Seneza C., Ogundare F.O. // Radiat. Meas. 2014. V. 66. P. 21.

[46] Milman I.I., Moiseykin E.V., Nikiforov S.V., Mikhailov S.G., Solomonov V.I. // Radiat. Meas. 2004. V. 38. N 4-6. P. 443. doi 10.1016/j.radmeas.2004.01.037

[47] Nikiforov S.V., Lushchik A., Nagirnyi V., Romet I., Ananchenko D.V., Moiseykin E.V., Ponomareva A.I. // Radiat. Meas. 2019. V. 122. P. 29. doi 10.1016/j.radmeas.2019.01.009 